\title{
Factors associated with nonattendance at clinical medicine scheduled outpatient appointments in a university general hospital
}

This article was published in the following Dove Press journal:

Patient Preference and Adherence

7 November 2013

Number of times this article has been viewed

\author{
Diego Giunta ${ }^{1,2}$ \\ Agustina Briatore 3 \\ Analía Baum ${ }^{3}$ \\ Daniel Luna ${ }^{3}$ \\ Gabriel Waisman² \\ Fernán Gonzalez Bernaldo \\ de Quiros ${ }^{1-3}$ \\ 'Internal Medicine Research Unit, \\ ${ }^{2}$ Internal Medicine Department, \\ ${ }^{3}$ Health Informatics Department, \\ Hospital Italiano de Buenos Aires, \\ Buenos Aires, Argentina
}

Correspondence: Agustina Briatore Internal Medicine Department. Hospital Italiano de Buenos Aires, Juan D Perón 4I90 (CI I8|ACH), Buenos Aires, Argentina

Tel +54 II 4959200

Email agusbriatore@gmail.com
Introduction: Nonattendance at scheduled outpatient appointments for primary care is a major health care problem worldwide. Our aim was to estimate the prevalence of nonattendance at scheduled appointments for outpatients seeking primary care, to identify associated factors and build a model that predicts nonattendance at scheduled appointments.

Methods: A cohort study of adult patients, who had a scheduled outpatient appointment for primary care, was conducted between January 2010 and July 2011, at the Italian Hospital of Buenos Aires. We evaluated the history and characteristics of these patients, and their scheduling and attendance at appointments. Patients were divided into two groups: those who attended their scheduled appointments, and those who did not. We estimated the odds ratios (OR) and corresponding 95\% confidence intervals (95\% CI), and generated a predictive model for nonattendance, with logistic regression, using factors associated with lack of attendance, and those considered clinically relevant. Alternative models were compared using Akaike's Information Criterion. A generation cohort and a validation cohort were assigned randomly.

Results: Of 113,716 appointments included in the study, 25,687 were missed $(22.7 \%$; $95 \%$ CI: $22.34 \%-22.83 \%)$. We found a statistically significant association between nonattendance and age (OR: 0.99 ; 95\% CI: 0.99-0.99), number of issues in the personal health record (OR: 0.98; 95\% CI: 0.98-0.99), time between the request for and date of appointment (OR: $1 ; 95 \% \mathrm{CI}$ : 1-1), history of nonattendance (OR: 1.07; 95\% CI: 1.07-1.07), appointment scheduled later than 4 pm (OR: 1.30; 95\% CI: 1.24-1.35), and specific days of the week (OR: $1.00 ; 95 \% \mathrm{CI}$ : 1.06-1.1). The predictive model for nonattendance included characteristics of the patient requesting the appointment, the appointment request, and the actual appointment date. The area under the receiver operating characteristic curve of the predictive model in the generation cohort was 0.892 (95\% CI: 0.890-0.894).

Conclusion: Evidence related to patient characteristics, and the identification of appointments with a higher likelihood of nonattendance, should promote guided strategies to reduce the rate of nonattendance, as well as to future research on this topic. The use of predictive models could further guide management strategies to reduce the rate of nonattendance.

Keywords: nonattendance, appointments, schedules

\section{Introduction}

Nonattendance at scheduled appointments at outpatient clinics is a common problem in general medical practice, representing a significant cost to the health care system, and resulting in disruption of daily work planning. ${ }^{1-3}$ Nonattendance at medical appointments has consequences not only for doctors (as it requires a greater use of resources and time), but also for patients, because there may be deterioration in the quality of care, and dissatisfaction associated with delays in obtaining a new appointment. ${ }^{4-8}$ 
Previous studies have reported that nonattendance at scheduled appointments is most frequently associated with those patients attending follow-up appointments, generally those assigned to another professional, those with appointments on Fridays, and those with appointments assigned 1 - 2 weeks in advance. Nonattendance was also associated with younger patient age, greater psychological problems, and lower socioeconomic status. ${ }^{9,10}$ Furthermore, in patients with chronic diseases, the nonattendance rate was also reported to be lower. ${ }^{1,3}$ Clinical patient characteristics can be important predictors of nonattendance, but they required high quality electronic health records to predict nonattendance accurately. ${ }^{1,9}$

In the United States and Europe, the nonattendance rate is estimated to be between $6.5 \%-55 \% ;^{2,3}$ there is little evidence regarding nonattendance in Latin America. Many studies have described the prevalence and impact of nonattendance at scheduled medical appointments, and possible strategies to decrease the nonattendance rate. However, few studies have utilized the characteristics associated with nonattendance for building predictive models, which might better identify those patients who may not attend a scheduled appointment.

Because nonattendance is a common problem, our objectives were to estimate the prevalence of nonattendance at clinical medicine outpatient offices, to identify the characteristics of appointments for which nonattendance was more likely to occur, and to generate a predictive model that could be applied to each appointment to estimate the probability of nonattendance.

\section{Materials and methods}

A retrospective cohort of adult patients (aged 18 years or older) was evaluated, which included patients who requested a scheduled appointment at the Clinical Medicine Outpatient care system at the Italian Hospital of Buenos Aires (HIBA). In this health care system, clinical medicine specialists fulfill the role of family medical practitioners; they are essential in primary care and monitoring of ambulatory patients. HIBA is a university general hospital in the Autonomous City of Buenos Aires that includes two hospitals (Central Hospital and Hospital Italiano de San Justo Agustin Rocca) and twenty-two primary care centers. This organization provides 750 beds, receives approximately 2.5 million outpatient visits per year, and includes a health maintenance organization that delivers prepaid health care to approximately 150,000 members per year: the Italian Hospital Health Plan (HP).

We included all requested appointments (random consecutive sampling) between January 2010 and October 2011. The sample was randomized to allocate a generation cohort (two-thirds of the sample) and a validation cohort (one third of the sample).
All data evaluated came from high quality secondary administrative databases. Exclusion criteria consisted of: appointments for specialties other than clinical medicine, and those assigned to procedures, preoperative appointments, specific consultations for evaluation prior to entry into the HP (pre-enrollment), emergency assessments, and spontaneously-assigned appointments, made at the time of the provision of care (ie, "squeeze in" appointments, with a medical indication care note). All cancelled appointments were also excluded.

The unit of analysis was the requested appointment. It was categorized as present, or absent, according to whether the patient attended the consultation, or not. Evaluations included 1) baseline patient characteristics (age, sex, medical coverage, number of medical problems in the EHR, distance from home to the appointment location), 2) characteristics of the appointment reservation process (method used to request the appointment, scheduling an additional alternative appointment or a conventional appointment, time from request to appointment), 3) patient history (number of requested appointments, percentages of missed appointments in the last year prior to requesting the appointment, prior hospitalization or current admission to hospital), and 4) characteristics of the appointment (location, if first appointment, time of day, day of week, month, percentage of appointments missed by the physician, record of weather on the day of the appointment).

To simplify the analysis, we dichotomized the month and hour of appointment, according to the following definitions: June, July, and December were considered to be "months with low attendance" (greater than 23.5\% missed appointments), and times after 5 pm were considered to be "high nonattendance hours". These two definitions were defined ad hoc using information from the generation cohort.

To evaluate the association of nonattendance with the distance between (A) the patient's home and (B) the location of the requested appointment, the coordinates of $\mathrm{A}$ and $\mathrm{B}$, in radians (latitude and longitude), were located by georeferencing. Coordinates were assigned using a non commercial mapping software for Buenos Aires city, developed by the Department of Health Informatics at HIBA. The coordinates of the center point of the patient's province of origin were used to represent the home address for patients whose addresses where outside Buenos Aires city. The distance between both pairs of coordinates (A and B), in kilometers, was calculated using the following formula: distance $=6,371 \times \operatorname{arccosine}(\operatorname{cosine}($ Latitude $A) \times$ cosine $($ Latitude $\mathrm{B}) \times \operatorname{cosine}($ Longitude $\mathrm{B}$-Longitude $\mathrm{A})+$ sine $($ Latitude A) $\times \operatorname{sine}($ Latitude $B)$ ). The distance calculated using this formula was only an approximation, as it 
considered only the linear distance between two points over the curved surface of the earth at sea level.

Climate data for the Autonomous City of Buenos Aires for the assessment period were requested from the Meteorological Information Center of the National Meteorological Service (http://www.smn.gov.ar). The associations between nonattendance and maximum, minimum, and average temperatures, and rainfall were evaluated.

Using the generation cohort, univariate association was assessed between each characteristic and nonattendance of appointments, using a multilevel logistic regression model, considering the natural clustering between scheduled appointments for the same patient. Each patient was considered as a cluster, or level, in the multilevel model. Odds ratios (ORs) were estimated for nonattendance at appointments with corresponding 95\% confidence intervals (95\% CI).

A multivariate multilevel logistic regression model was used for generating predictive models of nonattendance. Significant variables in univariate analysis were incorporated into the model, along with those considered relevant, even though not significant in univariate analysis. The presence of interaction was tested with the generation of interaction terms. The reliability of the estimate of the quadrature model was tested, and only models with relative differences lower than 0.01 for each estimated parameter were considered as candidates.

Diagnostic performance of the model was evaluated using receiver operating characteristic (ROC) curves for the predicted values of nonattendance at scheduled appointments, which were calculated using the estimated predictive model. We used the accuracy approximated by the area under the ROC curve as a goodness-of-fit measure. Different models were compared using Akaike's Information Criterion (AIC). The model with the largest area under the ROC curve and the lowest AIC was selected, then the selected predictive model was validated, using the validation cohort, by comparing predicted values with those observed.

To compare the predictive performance of the model with the observed proportion of nonattendance, we used the validation cohort. We stratified every appointment from the validation cohort according to the probability predicted by the model, in deciles. We calculated the average probability of nonattendance predicted by the model (the average of individual estimated probabilities), and the observed probability (proportion of nonattendance), within each decile stratum. The predicted and observed probabilities are shown, for each decile, in Table 4.

A $P$-value of less than $5 \%$ was considered statistically significant. The analysis was performed using SPSS version
17.0 (IBM Corp, Armonk, NY, USA) and Stata version 11.0 (StataCorp LP, College Station, TX, USA).

\section{Results}

A total of 170,574 requested appointments were included, corresponding to 44,402 patients. Requested and selected appointments are shown in Figure 1.

A trimodal age pattern was found, with peaks between 30-34 years, 65-69 years, and 80-84 years. The percentage of female patients was $62.1 \%(27,593)$. Seventy-five percent $(33,286)$ of the patients were affiliated with the HP. The frequency of nonattendance for all appointments was $22.7 \%$ (38,758), with 95\% CI: $22.52 \%-22.92 \%$. Baseline characteristics and appointment features are shown in Table 1.

The generation cohort included 113,716 scheduled appointments. The frequency of nonattendance at appointments was $22.6 \%$ (25,687), with 95\% CI: $22.34 \%-22.83 \%$. The association between different characteristics and nonattendance is shown in Table 2. For generation of the predictive model, the distance variable was excluded, due to lack of data for georeferencing patient home addresses (only 78,242 of 113,716 appointments had a patient address documented).

The predictive model selected included months of low attendance, first time appointments, the time from the assignment of the appointment to the appointment date, hospital admission at the time of the appointment, the appointment reservation system, hours of increased nonattendance, number of appointments requested on the same date, the patient's missed appointment rate in the year prior to the appointment, and milliliters of rainfall on the day of the appointment. The estimated coefficients are shown in Table 3. Age and sex were not included in the predictive model because, in the multivariable model, the association did not have statistical significance, and the model performance was worse than it was without these factors. In the generation cohort, the area under the ROC curve of the predictive model was 0.892 (95\% CI: 0.890-0.894) (Figure 2).

Using the predictive model in the validation cohort (56,858 appointments), the area under the ROC curve was estimated at 0.891 (95\% CI: 0.888-0.894). Using the validation cohort, predicted and observed probabilities were very similar, for each decile. The observed and predicted probabilities for each decile are shown in Table 4.

\section{Discussion}

The estimated prevalence of nonattendance at scheduled appointments with family medical practitioners is approximately 1 in 4 appointments. Nonattendance represents an important health care problem, which prolongs delays, and 


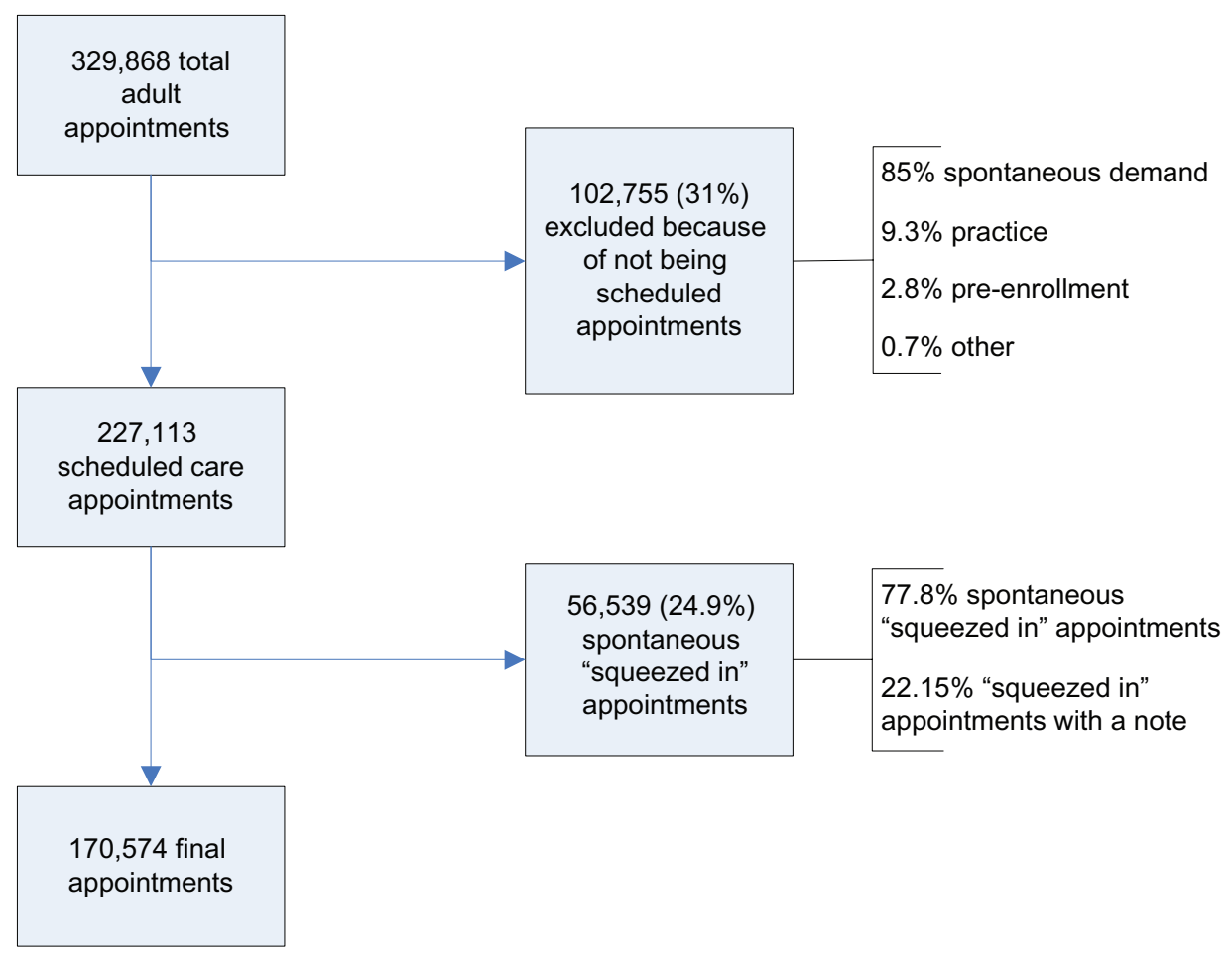

Figure I Selection and inclusion of appointments.

compromises the efficiency of primary care delivery, and the health care of the patient. ${ }^{4}$ While the prevalence of nonattendance is extremely variable, the estimate in our study was similar to those reported in other countries regarding nonattendance in primary care settings, such as in the United States (5\%-55\%, in different series), ${ }^{11}$ Saudi Arabia $(29.5 \%),{ }^{12}$ and Israel (36\%), ${ }^{13}$ although our rate was much higher than that previously described in the United Kingdom (6.5\%-7.7\%). ${ }^{1}$ Moreover, few studies have been conducted in Latin American populations.

Although it was not our aim to estimate costs, we observe that it has been claimed that nonattendance wastes substantial health care resources. However, this is only vaguely supported by empirical evidence. Literature regarding nonattendance reveals a great need for studies to address the nonattendance problem, by applying economic theory and analytical methods. ${ }^{3,14}$

The high prevalence of nonattendance may be related to cultural and social characteristics of the patients receiving care, to factors related to the health care system (management of medical scheduling, payment for service delivery or payment per capita, and public or private setting), and to the type of medical specialty.

According to previously reported findings, patients who miss their scheduled appointments are generally young adults, aged 17-40 years, ${ }^{1}$ and the likelihood of missing an appointment decreases with age. ${ }^{15}$ Some studies have found a with probability of nonattendance in females, compared against males (lower ${ }^{15}$ or higher ${ }^{2}$ odds of nonattendance), whereas we found no difference between sexes. Even though age was associated with nonattendance in univariate analysis, the tests for both coefficients of age and sex were not significant in multivariate predictive models. They were not included in the final predictive model, because the predictive models that included these variables performed worse than the models that excluded them.

In this study, lower nonattendance days included Wednesday and Thursday; this contrasts with other studies that reported lower rates of missed appointments on Mondays, as compared with Fridays. ${ }^{16,17}$ We found no evidence in the literature with regard to any associations between greater probability of nonattendance and climate, month of year, or day of the week. Most studies, including ours, agree that nonattendance is associated with a greater time period between requesting the appointment and the appointment date. ${ }^{17-20}$ In some studies, a history of nonattendance at previous appointments does function as a predictor, ${ }^{11,15}$ while this has not been observed in other studies. ${ }^{2,17}$

Most previous studies that describe nonattendance at medical appointments have considered a short time span. Because the time of year may influence nonattendance rates, it 
Table I Baseline characteristics of all grouped appointments (including the generation and validation cohort)

\begin{tabular}{|c|c|}
\hline \multicolumn{2}{|c|}{ Appointment characteristics ( 170,574 appointments) } \\
\hline \multicolumn{2}{|l|}{ Patient baseline characteristics } \\
\hline Age $(\text { years })^{\mathrm{a}}$ & $\begin{array}{l}68.5(39.69 \\
43.07-82.76)\end{array}$ \\
\hline Age $>65$ years & $54.5 \%(92,946)$ \\
\hline Male & $35.3 \%(60,28 I)$ \\
\hline \multicolumn{2}{|l|}{ Medical coverage } \\
\hline Italian Hospital Health Plan & $87.3 \%(148,862)$ \\
\hline High default rate & $12 \%(20,394)$ \\
\hline Private & $0.8 \%(1,3 \mid 8)$ \\
\hline Number of medical problems from the EHR ${ }^{a}$ & $14(12 ; 9-21)$ \\
\hline \multicolumn{2}{|l|}{ Patient medical records } \\
\hline Number of appointments requested in the last year ${ }^{a}$ & $3(4 ; 3-8)$ \\
\hline \multirow{2}{*}{ Percentage of defaults in the last year ${ }^{a}$} & 0 (33.33; \\
\hline & $0-33.33)$ \\
\hline Previous hospitalization & $63.8 \%(108,860)$ \\
\hline Hospitalized at the time of the appointment & I.4\% $(2,365)$ \\
\hline
\end{tabular}

\section{Appointment request}

Reservation type

Phone

In person

Web

EHR

Type of appointment

Conventional

Scheduled "squeezed in"

Time to appointment (days) ${ }^{\mathrm{a}}$

Appointment characteristics

Care location

Central Hospital

San Justo Hospital

Other

First appointment

Hour of the day

7

8

9

10

II

12

13

14

15

16

17

18

19

20

Day of the week

Monday

Tuesday

Wednesday

Thursday

Friday

Saturday

Month of the year

January

February
$43.4 \%(73,073)$

$44.9 \%(75,531)$

$3.4(5,757)$

$8.2(13,855)$

$99.5 \%(167,410)$

$0.5 \%(806)$

$16(18.93)$

$42.5 \%(72,560)$

$7.2 \%(12,352)$

$50.2 \%(85,662)$

$9.7 \%(16,265)$

$0.0 \%(73)$

$6.4 \%(10,973)$

$11.6 \%(19,831)$

II. $8 \%(20,207)$

$9.9 \%(16,952)$

$6.3 \%(10,823)$

$8.7 \%(14,887)$

$9.8 \%(16,698)$

$9.1 \%(15,546)$

$9.1 \%(15,569)$

$9.1 \%(15,588)$

$5.5 \%(9,454)$

$2.3 \%(3,965)$

$0.0 \%(8)$

$24 \%(40,982)$

$20 \%(34,172)$

$19.7 \%(33,578)$

$20.9 \%(35,590)$

$15.2 \%(25,92 \mathrm{I})$

$0.2 \%(331)$

$9.7 \%(16,544)$

$7.6 \%(12,906)$
Table I (Continued)

\begin{tabular}{|c|c|}
\hline March & II.5\% (19,688) \\
\hline April & II.6\% (19,715) \\
\hline May & II\% (I8,789) \\
\hline June & $11 \%(18,720)$ \\
\hline July & $10.2 \%(17,389)$ \\
\hline August & $5.9 \%(9,992)$ \\
\hline September & $5.6 \%(9,553)$ \\
\hline October & $4.7 \%(8,064)$ \\
\hline November & $5.7 \%(9,779)$ \\
\hline December & $5.5 \%(9,435)$ \\
\hline \multirow[t]{2}{*}{ Minimum temperature $\left({ }^{\circ} \mathrm{C}\right)^{\mathrm{a}}$} & I 3.4 (9.30; \\
\hline & $9.2-18.5)$ \\
\hline \multirow[t]{2}{*}{ Average temperature $\left({ }^{\circ} \mathrm{C}\right)^{\mathrm{a}}$} & I7.5 (9.70; \\
\hline & 13.2-22.9) \\
\hline \multirow[t]{2}{*}{ Maximum temperature $\left({ }^{\circ} \mathrm{C}\right)^{\mathrm{a}}$} & 23.2 (10.10; \\
\hline & |8-28.1) \\
\hline Rainfall $(\mathrm{mm})^{\mathrm{a}}$ & $0(0.10 ; 0-0.1)$ \\
\hline
\end{tabular}

is necessary to evaluate longer periods. This strategy revealed higher rates of nonattendance during the holiday months (June, July, and December), which also correspond to the period of the year with the most extreme temperatures. It may not be that modifying the appointment schedule during this period could have an impact on the attendance rate.

A system for reducing the rate of nonattendance, that requires primary data collection, would be costly and would require numerous resources. However, in our study, the data associated with nonattendance at scheduled appointments were obtained from secondary databases, which enabled estimation of the probability of nonattendance for each request, without requiring additional information. This approach may further aid in developing strategies for targeted reminders, or in developing an appointment reservation system that shows the estimated probability of nonattendance, for each free appointment, for a specific patient, each time a new appointment is required. In this latter case, the administrator could offer patients appointments that are associated with lower estimated probabilities of nonattendance. Optimizing a more efficient appointment scheduling system, using predictive models of this type, will require further information regarding the causes of attendance, nonattendance, and appointment cancellation.

The advantages of using secondary databases are well known, ${ }^{21}$ although this approach also has disadvantages. ${ }^{22}$ In our study, typing errors and lost data corresponding to the addresses of patients made it impossible to georeference the data in order to evaluate the effect of distance on nonattendance in the predictive model, even though it was significantly associated in univariate analysis. Missing data is a common disadvantage of using secondary databases. 
Table 2 Association between patient and appointment characteristics and nonattendance in the generation cohort (I 13,716 scheduled appointments)

\begin{tabular}{|c|c|c|c|}
\hline & OR & $95 \% \mathrm{Cl}$ & $P$ \\
\hline \multicolumn{4}{|l|}{ Baseline characteristics } \\
\hline Age (per I year increase) & 0.99 & $0.99-0.99$ & $<0.001$ \\
\hline Age $>65$ years & 0.69 & $0.66-0.71$ & $<0.001$ \\
\hline Male & 0.96 & $0.92-1.0$ & 0.101 \\
\hline Italian Hospital Health Plan & 0.54 & $0.5 I-0.56$ & $<0.001$ \\
\hline Number of issues in the EHR & 0.98 & $0.98-0.99$ & $<0.001$ \\
\hline $\begin{array}{l}\text { Distance from home to care } \\
\text { location (per I km increase) }\end{array}$ & 0.97 & $0.96-0.97$ & $<0.001$ \\
\hline \multicolumn{4}{|l|}{ Patient medical records } \\
\hline $\begin{array}{l}\text { Number of appointments } \\
\text { requested in the last year } \\
\text { (per I appointment increase) }\end{array}$ & 0.99 & $0.99-1.0$ & 0.067 \\
\hline $\begin{array}{l}\text { Percentage of defaults in the } \\
\text { last year (per I\% increase) }\end{array}$ & 1.07 & $1.07-1.07$ & $<0.001$ \\
\hline Previous hospitalization & 1.13 & $1.09-1.17$ & $<0.001$ \\
\hline $\begin{array}{l}\text { Hospitalized at the time } \\
\text { of the appointment }\end{array}$ & 3.35 & $2.94-3.82$ & $<0.001$ \\
\hline First appointment & 1.58 & $1.5-1.67$ & $<0.001$ \\
\hline \multicolumn{4}{|l|}{ Appointment request } \\
\hline \multicolumn{4}{|l|}{ Reservation type } \\
\hline Phone $^{\mathrm{a}}$ & $\begin{array}{l}1.0 \\
\text { (reference) }\end{array}$ & & \\
\hline In person & 1.13 & $0.92-0.99$ & 0.031 \\
\hline Web & 0.89 & $0.8-0.99$ & 0.034 \\
\hline EHR & 3.34 & $3.15-3.55$ & 0.001 \\
\hline Type of appointment & 0.90 & $0.7 I-1.13$ & 0.384 \\
\hline $\begin{array}{l}\text { Time to appointment } \\
\text { (per I day increase) }\end{array}$ & 1.0022 & $1.00 \mathrm{I}-1.0034$ & $<0.001$ \\
\hline \multicolumn{4}{|l|}{ Appointment characteristics } \\
\hline \multicolumn{4}{|l|}{ Care location } \\
\hline Central Hospital $^{a}$ & I & & \\
\hline San Justo Hospital & (reference) & $1.33-1.54$ & $<0.001$ \\
\hline Others & $\begin{array}{l}1.43 \\
0.88\end{array}$ & $0.85-0.92$ & $<0.001$ \\
\hline \multicolumn{4}{|l|}{ Hour of the day } \\
\hline $7^{a}$ & $\begin{array}{l}1.0 \\
\text { (reference) }\end{array}$ & & \\
\hline 8 & 0.97 & $0.43-2.15$ & 0.944 \\
\hline 9 & 0.87 & $0.39-1.92$ & 0.734 \\
\hline 10 & 0.85 & $0.38-1.9$ & 0.706 \\
\hline 11 & 0.87 & $0.39-1.94$ & 0.750 \\
\hline 12 & 0.96 & $0.43-2.13$ & 0.923 \\
\hline 13 & 0.85 & $0.38-1.89$ & 0.699 \\
\hline 14 & 0.92 & $0.4 I-2.05$ & 0.850 \\
\hline 15 & 0.91 & $0.4 I-2.0 I$ & 0.816 \\
\hline 16 & 0.99 & $0.45-2.21$ & 0.995 \\
\hline 17 & 1.15 & $0.52-2.55$ & 0.726 \\
\hline 18 & 1.18 & $0.53-2.62$ & 0.680 \\
\hline 19 & 1.33 & $0.6-2.98$ & 0.475 \\
\hline Time over 16 hours & 1.30 & $1.24-1.35$ & $<0.001$ \\
\hline \multicolumn{4}{|l|}{ Day of the week } \\
\hline Monday ${ }^{a}$ & $\begin{array}{l}1.0 \\
\text { (reference) }\end{array}$ & & \\
\hline Tuesday & 0.97 & $0.92-1.02$ & 0.364 \\
\hline
\end{tabular}

Table 2 (Continued)

\begin{tabular}{|c|c|c|c|}
\hline & OR & $95 \% \mathrm{Cl}$ & $P$ \\
\hline Wednesday & 0.93 & $0.88-0.97$ & 0.005 \\
\hline Thursday & 0.92 & $0.88-0.97$ & 0.003 \\
\hline Friday & 0.98 & $0.93-1.04$ & 0.596 \\
\hline Saturday & 1.57 & I.I-2.24 & 0.012 \\
\hline $\begin{array}{l}\text { Low nonattendance days } \\
\text { (Wednesday and Thursday) }\end{array}$ & 1.06 & I.06-I.I & $<0.001$ \\
\hline \multicolumn{4}{|l|}{ Month of the year } \\
\hline January ${ }^{\mathrm{a}}$ & $\begin{array}{l}1.0 \\
\text { (reference) }\end{array}$ & & \\
\hline February & 1.07 & $0.99-1.15$ & 0.072 \\
\hline March & 1.04 & $0.97-1.12$ & 0.198 \\
\hline April & 0.94 & $0.88-1.01$ & 0.118 \\
\hline May & 0.96 & $0.9-1.03$ & 0.363 \\
\hline June & 1.09 & $1.02-1.17$ & 0.009 \\
\hline July & 1.16 & I.08-I.24 & 0.001 \\
\hline August & 0.99 & $0.91-1.08$ & 0.962 \\
\hline September & 0.99 & $0.9-1.07$ & 0.818 \\
\hline October & 0.98 & $0.9-1.08$ & 0.795 \\
\hline November & 0.90 & $0.82-0.98$ & 0.015 \\
\hline December & 1.13 & $1.03-1.22$ & 0.004 \\
\hline $\begin{array}{l}\text { Months with highest defaults } \\
\text { (June, July, and December) }\end{array}$ & 1.13 & $1.09-1.18$ & 0.001 \\
\hline $\begin{array}{l}\text { Minimum temperature } \\
\text { (per } 1^{\circ} \mathrm{C} \text { increase) }\end{array}$ & 1.0 & $0.99-1.0$ & 0.807 \\
\hline $\begin{array}{l}\text { Average temperature } \\
\text { (per } 1^{\circ} \mathrm{C} \text { increase) }\end{array}$ & 0.99 & $0.99-1.0$ & 0.173 \\
\hline $\begin{array}{l}\text { Maximum temperature } \\
\text { (per } 1^{\circ} \mathrm{C} \text { increase) }\end{array}$ & 0.99 & $0.99-1.0$ & 0.053 \\
\hline $\begin{array}{l}\text { Rainfall (per I mm rainfall } \\
\text { increase) }\end{array}$ & 1.0032 & $1.0018-1.0045$ & $<0.001$ \\
\hline
\end{tabular}

Note: aReference category.

Abbreviations: OR, odds ratio; $\mathrm{Cl}$, confidence interval; $\mathrm{EHR}$, electronic health records.

The inclusion of clinical data, such as cognitive impairment, in the predictive model could be useful in predicting nonattendance at scheduled appointments. ${ }^{1}$ However, these models strongly depend on the quality of the data used to develop them. The main difficulty lies with the specificity and sensitivity of diagnoses, in clinical data obtained from the electronic medical records. ${ }^{23,24}$ For example, due to privacy concerns, many psychiatric diagnoses are not submitted by specialists to electronic medical records..$^{25}$ Other studies of factors associated with nonattendance have also excluded this type of data in their analyses. ${ }^{15}$ Additionally, using clinical data from EHR usually considers everyone who does not have a medical problem registered in their medical record as not having that medical problem. For example, if a patient does not have the problem "hypertension" in their medical records, it is considered that they do not have hypertension; in fact, their hypertension status is unknown. Secondary administrative databases' information as to the rate of nonattendance in the last year, and the time of the scheduled appointment, 
Table 3 All variables included in the full predictive model

\begin{tabular}{|c|c|c|c|c|c|}
\hline Included variable & $\begin{array}{l}\text { Estimated coefficient } \\
\text { (beta regression coefficient) }\end{array}$ & $\begin{array}{l}\text { Standard } \\
\text { error }\end{array}$ & $95 \% \mathrm{Cl}$ & OR & $\mathbf{P}$ \\
\hline Months of low attendance & 0.175 & 0.021 & $0.134-0.215$ & 1.19 & $<0.001$ \\
\hline First-time appointments & -0.21 & 0.355 & $-0.279-0.14$ & 0.81 & $<0.001$ \\
\hline $\begin{array}{l}\text { Time from assignment of appointment } \\
\text { to appointment date (per I day increase) }\end{array}$ & 0.006 & 0.000 & $0.004-0.007$ & 1.0059 & $<0.001$ \\
\hline Hospitalized at the time of the appointment & 0.778 & 0.068 & $0.645-0.912$ & 2.17 & $<0.001$ \\
\hline In-person appointment reservation & 0.121 & 0.021 & $0.08-0.162$ & 1.12 & $<0.001$ \\
\hline Health website appointment reservation & 0.123 & 0.052 & $0.02-0.226$ & 1.13 & 0.019 \\
\hline Appointment reservation by EHR & 1.084 & 0.031 & $1.022-1.145$ & 2.95 & $<0.001$ \\
\hline Later nonattendance hours ( $5 \mathrm{pm}$ or later) & 0.062 & 0.025 & $0.013-0.11$ & 1.06 & 0.012 \\
\hline Number of appointments requested on the same date & 0.013 & 0.002 & $0.009-0.017$ & 1.01 & $<0.001$ \\
\hline $\begin{array}{l}\text { Default rate of the patient in the year before } \\
\text { the appointment (per } 1 \% \text { increase) }\end{array}$ & $0.07 I$ & 0.000 & $0.07-0.072$ & 1.07 & $<0.001$ \\
\hline Milliliters of rainfall (per I mm of rainfall increase) & 0.002 & 0.001 & $0-0.003$ & 1.0023 & 0.002 \\
\hline Constant & -3.788 & 0.032 & $-3.85-3.726$ & & $<0.001$ \\
\hline
\end{tabular}

Abbreviations: $\mathrm{OR}$, odds ratio; $\mathrm{Cl}$, confidence interval; EHR, electronic health records.

have almost perfect data quality, and may represent appropriated proxies for estimating the probability of nonattendance. Administrative and demographic data, such as age, date of birth, race, place of residence, and date of death are considered largely reliable and valid for our type of model, which is why they were prioritized in this study ${ }^{26}$

The predictive model we generated works best in patients with a greater chance of nonattendance (ie, there is better concordance between predicted and observed values in patients with a higher probability of missed appointments), as shown

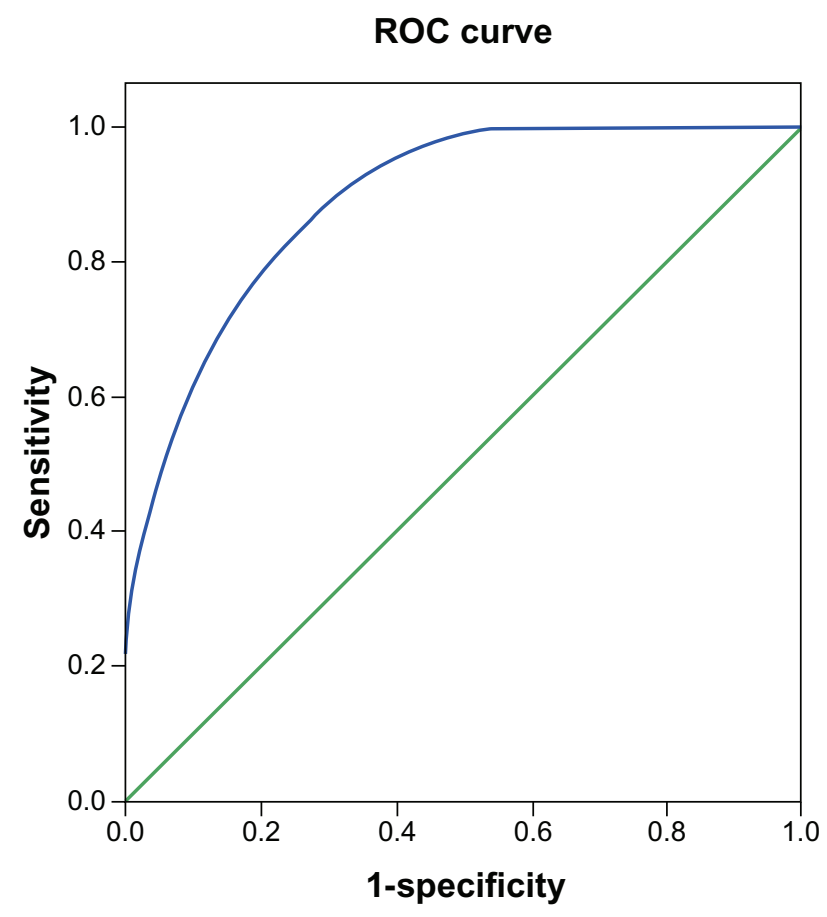

Figure 2 ROC curve of predicted probabilities for the generation cohort. Abbreviation: ROC, receiver operating characteristic. in Table 4. Characteristics that predict a higher probability of missing an appointment include 1) patients with higher default rate in the year before the appointment, 2) higher number of appointments requested on the same date, 3) longer time from assignment of appointment to appointment date, 4) non-first time appointment, with appointment reserved using any system but phone, and 5) appointment scheduled at hour or month of low attendance. This could be representative of a kind of personality, which tends to have a higher rate of nonattendance, even though we could not specify this type of personality.

Additionally, the area under the ROC curve of the predicted model was large; the use of an external validation cohort might be useful for evaluation of its performance. There are also significant technical difficulties associated with generating external validation cohorts with similar characteristics, and their usefulness may be limited, because there could be variability across cohorts from different geographical areas or health systems. Therefore, there is a

Table 4 Observed and expected probabilities for each decile of predicted values in the validation cohort

\begin{tabular}{llll}
\hline Decile & $\begin{array}{l}\text { Number of } \\
\text { observations }\end{array}$ & $\begin{array}{l}\text { Observed } \\
\text { probabilities }\end{array}$ & $\begin{array}{l}\text { Predicted } \\
\text { probabilities }\end{array}$ \\
\hline 1 & 5,599 & 0 & 0.024 \\
2 & 5,610 & 0 & 0.028 \\
3 & 5,613 & 0 & 0.032 \\
4 & 5,612 & 0.028 & 0.046 \\
5 & 5,606 & 0.113 & 0.083 \\
6 & 5,609 & 0.187 & 0.128 \\
7 & 5,608 & 0.277 & 0.201 \\
8 & 5,608 & 0.358 & 0.323 \\
9 & 5,608 & 0.503 & 0.541 \\
10 & 5,608 & 0.839 & 0.887 \\
\hline
\end{tabular}


need for similar studies in other populations, to estimate the probabilities of nonattendance under local conditions.

The importance of this study lies principally in the ability to predict nonattendance using databases that are simple to acquire, from high-quality, nonclinical, secondary sources. This capacity could facilitate preventive measures to reduce nonattendance, by addressing patients who are more likely to fail to attend a scheduled appointment. We believe that there are few associated factors that modify nonattendance, and also that they do not represent the cause of nonattendance. This leads us to consider it not an effective strategy to approach this issue by modifying those associated factors. Additionally, we believe that changing the schedule of appointments, in the day and hours correlated with higher chances of nonattendance, will not be effective either, as it probably reflects a particular type of patient who take turns in to these times and days.

Characterizing and identifying appointments that have increased probability for nonattendance would make it possible to apply strategies to reduce the nonattendance rate. Moreover, development of future research on this topic can generate new tools for addressing the problem of nonattendance, which affects all aspects of health care.

\section{Disclosure}

The authors report no conflicts of interest in this work.

\section{References}

1. George A, Rubin G. Nonattendance in general practice: a systematic review and its implications for access to primary health care. Fam Pract. 2003;20(2):178-184.

2. Neal RD, Lawlor DA, Allgar V, et al. Missed appointments in general practice: retrospective data analysis from four practices. Br J Gen Pract. 2001;51(471):830-832.

3. Waller J, Hodgkin P. Defaulters in general practice: who are they and what can be done about them? Fam Pract. 2000;17(3):252-253.

4. Husain-Gambles M, Neal RD, Dempsey O, Lawlor DA, Hodgson J. Missed appointments in primary care: questionnaire and focus group study of health professionals. Br J Gen Pract. 2004;54(499):108-113.

5. Perron NJ, Dao MD, Kossovsky MP, et al. Reduction of missed appointments at an urban primary care clinic: a randomised controlled study. BMC Fam Pract. 2010;11:79.

6. New statistics on outpatients' care confirm millions of missed appointments. New J (Inst Health Rec Inf Manag). 2006;47(4):17.

7. Capko J. The price you pay for missed appointments. J Med Pract Manage. 2007;22(6):368.
8. Alcolea Guerrero M, Gorgemans S. [Absenteeism of patients given appointments in Specialized Care medical offices in the consortium of the High Resolution Aragon Health Care: Economic repercussions and delays.] Absentismo de pacientes citados en las consultas de Atención Especializada del Consorcio Aragonés Sanitario de Alta Resolución: repercusión económica y demoras. Rev Adm Sanit. 2009;7(4):715-728. Spanish.

9. Hamilton W, Round A, Sharp D. Patient, hospital, and general practitioner characteristics associated with nonattendance: a cohort study. Br J Gen Pract. 2002;52(477): 317-319.

10. Leung GM, Castan-Cameo S, McGhee SM, Wong IO, Johnston JM. Waiting time, doctor shopping, and nonattendance at specialist outpatient clinics: case-control study of 6495 individuals in Hong Kong. Med Care. 2003;41(11):1293-1300.

11. Goldman L, Freidin R, Cook EF, Eigner J, Grich P. A multivariate approach to the prediction of no-show behavior in a primary care center. Arch Intern Med. 1982;142(3):563-567.

12. al-Shammari SA. Failures to keep primary care appointments in Saudi Arabia. Fam Pract Res J. 1992;12(2):171-176.

13. Hermoni D, Mankuta D, Reis S. Failure to keep appointments at a community health centre. Analysis of causes. Scand J Prim Health Care. 1990;8(2):107-111.

14. Bech M. The economics of nonattendance and the expected effect of charging a fine on non-attendees. Health Policy. 2005;74(2):181-191.

15. Neal RD, Hussain-Gambles M, Allgar VL, Lawlor DA, Dempsey O. Reasons for and consequences of missed appointments in general practice in the UK: questionnaire survey and prospective review of medical records. BMC Fam Pract. 2005;6:47.

16. Smith CM, Yawn BP. Factors associated with appointment keeping in a family practice residency clinic. J Fam Pract. 1994;38(1):25-29.

17. Bickler CB. Defaulted appointments in general practice. $J R$ Coll Gen Pract. 1985;35(270):19-22.

18. Bean AG, Talaga J. Predicting appointment breaking. J Health Care Mark. 1995;15(1):29-34.

19. Oppenheim GL, Bergman JJ, English EC. Failed appointments: a review. J Fam Pract. 1979;8(4):789-796.

20. Hagerman GA. Testing the mailed appointment reminder in family practice. J Fam Pract. 1978;7(1):199-201.

21. Schneeweiss S, Avorn J. A review of uses of health care utilization databases for epidemiologic research on therapeutics. J Clin Epidemiol. 2005;58(4):323-237.

22. Terris DD, Litaker DG, Koroukian SM. Health state information derived from secondary databases is affected by multiple sources of bias. J Clin Epidemiol. 2007;60(7):734-741.

23. Hall RW. Handbook of Healthcare System Scheduling. New York: Springer; 2012.

24. Iezzoni LI. Assessing quality using administrative data. Ann Intern Med. 1997;127(8 Pt 2):666-674.

25. Luna D, Franco M, Plaza C, Otero C, et al. Accuracy of an electronic problem list from primary care providers and specialists. Stud Health Technol Inform. 2013;192:417-421.

26. Virnig B, Dotson Madeira A. Strengths and limitations of CMS administrative data in research. Cited 2012. Available from: http://www. resdac.org/resconnect/articles/156\#conclusion. Accessed August 20, 2013.
Patient Preference and Adherence

\section{Publish your work in this journal}

Patient Preference and Adherence is an international, peer-reviewed, open access journal focusing on the growing importance of patient preference and adherence throughout the therapeutic continuum. Patient satisfaction, acceptability, quality of life, compliance, persistence and their role in developing new therapeutic modalities and compounds to

\section{Dovepress}

optimize clinical outcomes for existing disease states are major areas of interest. This journal has been accepted for indexing on PubMed Central. The manuscript management system is completely online and includes a very quick and fair peer-review system. Visit http://www.dovepress.com/ testimonials.php to read real quotes from published authors. 